\title{
Um corpo sincopado: \\ uma discussão sobre a influência do samba no trabalho do ator Grande Otelo no Teatro de Revista Brasileiro
}

Deise de Brito

Mestre em Artes Cênicas/USP

Área de Concentração: Teoria e Prática do Teatro

Orientadora: Elizabeth Ferreira Cardoso Ribeiro Azevedo

Atriz, arte-educadora e, atualmente, supervisora de ações educativas no SESC Pompéia

Resumo: A proposta é apresentar o destaque do ator Grande Otelo no teatro de revista nas décadas de 1930 e 1940, abordando especificamente a sua reconstrução como artista desse gênero no Rio de Janeiro, as suas interpretações de tipos relacionados ao homem negro brasileiro, assim como a utilização do samba como seu material de trabalho.

Palavras-chave: fronteira, malandragem, samba

Title: A syncopated body: a discussion of the influence of samba in the work of the actor Grande Otelo in Brazilian Theater of Revue

Abstract: The proposal is to present the highlight of the actor Grande Otelo in the theater of revue in early decades (30's and 40's) of the $20^{\text {th }}$ century, approaching specifically his reconstruction as an artist of this kind of theater in Rio de Janeiro, his interpretations of characters related to the Brazilian Black man as well as the use of Samba as his working material.

Keywords: border, trickery, samba

Título: Un cuerpo sincopado: un análisis de la influencia de la samba en el trabajo del actor Grande Otelo en el Teatro de Revista Brasileño

Resumen: La propuesta es presentar lo más destacado del actor Grande Otelo en el teatro de revista en las décadas del 30 y 40 del siglo XX, abordando específicamente su reconstrucción como artista de este género en Rio de Janeiro, sus interpretaciones de tipos relacionadas al hombre negro brasileño, así como la utilización de samba, como su material de trabajo.

Palabras-clave: frontera, trampa, samba

\section{Um pouco de revista...}

O teatro de revista surgiu na França, no século XVIII. Com matriz popular, originou-se das feiras parisienses, extraindo das manifestações artísticas de rua sua essência contestadora e satírica da ordem social estabelecida e retirando da commedia dell'arte, a diretriz básica para a linha de interpretação dos artistas. Em suma: 
meio de inúmeros quadros, uma resenha, passando em revista fatos sempre inspirados na atualidade, utilizando jocosas caricaturas, com o objetivo de fornecer ao público uma alegre diversão (VENEZIANO, 1996, p. 28).

Um texto deste estilo teatral, pelo menos até o final da Primeira Guerra Mundial, propunha uma crítica humorada dos costumes, hábitos, acontecimentos e personalidades, geralmente conhecidos pelo espectador. Piadas, paródias, tipos e caricaturas eram integrados para fazer com que o espetáculo fosse bem recebido. $\mathrm{O}$ ato cômico já estava presente no todo e funcionava como uma espécie de conector entre os recursos: orquestra, coristas ou girls, vedetes, compères (no caso das revistas de ano do final do século XIX), galãs e outros atores.

Segundo Roberto Ruiz e Tânia Brandão, em 6 de janeiro de 1856, chegou ao Brasil a primeira revista, denominada Fossilismo e progresso, um espetáculo da Companhia Portuguesa (RUIZ; BRANDÃO, 1988).

A primeira revista brasileira, encenada em 1859, As surpresas do Senhor José Piedade, de Justiniano de Figueiredo Novaes, não obteve êxito junto ao público carioca e, para complementar, foi proibida de ser encenada. A peça era uma recapitulação dos principais fatos de 1858. Tinha como personagens o roceiro "Senhor José Piedade", fio condutor da peça; as figuras alegóricas relacionadas aos periódicos, como o "Mercantil”, "a Marmota", “o Jornal do Comércio"; além de um quadro denominado Asas de anjo, que fazia alusão a um espetáculo realista, cujo texto era de José de Alencar, e que fora proibido de continuar sendo encenado por apresentar diálogos imorais. Nessa cena, havia os personagens da "polícia" e da "censura", provavelmente satirizados. Acredita-se que esta seria uma das razões da proibição à continuidade das apresentações dessa revista (VENEZIANO, 1991, p. 26-27).

Outra revista só voltaria aos palcos em 1875, denominada A Revista de Ano de 1875, obtendo o mesmo nível de repercussão da anterior. O primeiro grande sucesso de uma revista no país só ocorreria em 1883, com a estreia de $O$ mandarim, cuja autoria é de Arthur Azevedo e Moreira Sampaio. Azevedo foi um dos principais responsáveis pelo êxito do gênero revisteiro no Brasil.

Trilhando um caminho bem-sucedido, o teatro de revista satisfez uma plateia variada em solos brasileiros, agregando profissionais das áreas da música, da dança, do teatro e da literatura. Ele permaneceu até meados da década de 1960, estando já nesse período bastante desgastado. Contudo, suas ramificações ainda apareceram nos shows 
Revista "AspaS" - № 1 - 2011 - Anais do Primeiro Seminário de Pesquisas em Andamento ppgac do Programa de Pós-Graduação em Artes Cênicas da Universidade de São Paulo.

dos cassinos, no cinema e nos programas de humor televisivos. Muitos artistas conhecidos atuaram nesse estilo teatral.

\section{Otelo, o grande revisteiro}

Grande Otelo iniciou sua carreira artística ainda criança, fazendo pequenas apresentações nas ruas de sua cidade natal, Uberlândia, e participando de cenas nos circos que visitavam aquela região. Otelo foi tutelado aos dez anos pela família da atriz Abigail Gonçalves, mudando-se para São Paulo por volta de 1925. O padrasto e a mãe da atriz dirigiam a Companhia de Comédias e Variedades Sarah Bernhaardt. Na companhia, ele aprendeu elocução e dicção para o teatro incorporando novas técnicas. Em 1926, foi o grande destaque da Companhia Negra de Revistas, sendo bem elogiado pelos críticos. Esse grupo foi fundado pelo artista D' Chocolat e pelo cenógrafo Jaime Silva, tendo a participação de figuras como Pixinguinha, Sebastião Cirino e Rosa Negra.

Em 1927, foi adotado pela família do senador Antônio de Queiroz. Entre o intervalo de adoção de uma família para outra, ele viveu nas ruas de São Paulo, no abrigo para menores e sob a guarda de mais dois tutores.

O trabalho deste ator no teatro de revista é o recorte da pesquisa de mestrado Um ator de fronteira: uma análise da trajetória do ator Grande Otelo no teatro de revista brasileiro entre as décadas de 20 e 40. Estudou-se a respectiva atmosfera social em que Otelo estava imerso a fim de verificar como ela interferiu em sua estética de atuação, analisando o uso de suas referências culturais, sua imagem construída pelo outro, a imagem construída por si próprio, bem como o cruzamento entre elas.

Foi estabelecido como método a proposta do historiador Timothy Clark tendo o seu texto As condições da criação artística (2007) como elemento norteador dos direcionamentos que tomamos. Entre as opções apresentadas, ela foi a que mais se mostrou compatível com o caminho da nossa discussão, a relação do trabalho de Otelo com o ciclo social.

Recorremos a esse historiador porque ele propõe um estudo sobre a obra de arte a partir das condições de criação do artista. Clark tem investigado nas últimas décadas sobre a produção de artistas como Jackson Polock e Cézanne, propondo novos caminhos e novas perspectivas de investigação, relacionados às obras. Em uma das suas formulações, ele apresenta o estudo sobre a utilização e a escolha dos "materiais 
ideológicos" como fator fundamental para a interpretação de um trabalho e o entendimento sobre a identidade de um artista.

Por ideologias (o conceito me parece ser sempre plural, embora todas as ideologias alimentam umas às outras e compartilhem a mesma função) entendo os corpos de crenças, imagens, valores e técnicas de representação pelos quais as classes sociais, em conflito umas com as outras, tentam "naturalizar" suas histórias particulares (CLARK, 2007, p. 336).

Para Clark, a obra tem uma ligação peculiar com os componentes, chamados por ele de materiais da ideologia. Analisar essa relação é um dos aspectos mais relevantes para o historiador. Segundo o estudioso, "ideologia é o que a obra de arte é e o que ela não é” (Ibidem, p. 336).

Os trabalhos do ator Grande Otelo foram considerados como obras de arte a serem apropriadas. Os mesmos são também formas ideológicas de uma época. A partir desta reflexão, torna-se um pouco mais fácil fazer a análise do caminho da carreira do ator, que participou de um tempo e de um movimento artístico (o teatro de revista), optando por ele e renunciando a outros. Assim, tenta-se superar as afirmações comuns sobre seu trabalho, tais como o contribuinte para a solidificação dos estigmas em relação ao ator afro-brasileiro ou a elevação da sua figura como patrimônio artístico nacional (condição que ele recusava a aceitar), analisando suas performances, personagens ou obras a partir do seu prisma, da sua posição sociocultural.

Recusando técnicas do chamado teatro "sério"1 e assimilando peculiaridades do teatro ligeiro, Otelo optava por uma linha teatral inserida dentro de um sistema com estrutura definida e regras específicas. Ao estabelecer essa escolha, ele contribuía para que o público construísse uma imagem a seu respeito.

A interpretação de Grande Otelo sugeriu não apenas trejeitos faciais característicos ou um modelo para construir tipos cômicos, mas acima de tudo uma forma de satirizar, mesmo que sutilmente, as complexidades de seu meio, entre elas o preconceito. Ele representou, outras vezes, a rendição a um sistema permeado de padrões e estigmas. Nesse caminho, de um lado a outro, ele desenvolveu suas ações cênicas formulando um conjunto de tipificações e caricaturas vivas, permeados de historicidades e discussões.

Em 1935, Otelo começa a trabalhar com Jardel Jércolis, um dos principais empresários de teatro de revista naquele momento. Ingressando na Companhia Jardel 
Jércolis, ele conseguiu a meta tão almejada, ir para o Rio de Janeiro, um dos principais centros de entretenimento do país e que ainda tinha no teatro musicado e em outros gêneros de variedades suas principais atrações.

O tipo consiste em ser contrário ao indivíduo, cujo perfil é imerso em um passado e num conjunto de conflitos. Já o personagem tipo é criado a partir de um cosmo externo (Cf. VENEZIANO, 1991). O teatro de revista tinha função de divertimento e, para atingir esse objetivo, ele articulava um sistema particular de convenções. Os tipos fazem parte desse sistema.

De acordo com Bergson, o homem é parte da natureza e, diferentemente dos outros animais, distingue coisas, seres, pessoas etc. por uma necessidade utilitária e classificatória. Porém, existe toda uma parte inclassificável a ser observada e vista, existem outras particularidades e é o artista quem percebe e nos faz perceber. Ele traz à tona as cores, os sons do mundo material, além dos sutis movimentos da vida interior. Dentro disso tudo, o drama revela uma realidade profunda, escondida, mas que a qualquer momento pode entrar em erupção. São sentimentos inimitáveis e individualizados.

A comédia, diferentemente, capta as generalidades das coisas e da vida real, criando tipos, ou seja, personagens com características gerais que podem ser ramificadas ou imitadas. Assim, o ator comediante necessita estar atento aos aspectos e às sutilezas, tanto das formas quanto das relações que o rodeia. Essa foi uma habilidade que Otelo precisou desenvolver a partir do meio que estava lhe sendo proposto, segundo suas condições de ator brasileiro e negro na cidade do Rio de Janeiro da década de 1930.

De acordo com levantamento realizado, analisando a participação de Otelo nos espetáculos da Companhia Jardel Jércolis (ANTUNES, 1996) - Ensaio geral (1934), Goal! (1935), Carioca (1935), Rio - Folies (1935), De ponta a ponta (1935), Maravilhosa (1936), Estupenda (1936), Magnífica (1936) e No tabuleiro da baiana (1937) -, concluímos que o ator interpretou continuamente tipos ligados ao samba. Isso o possibilitou a buscar no próprio mundo desse ritmo os artifícios e estratagemas necessários para seu trabalho. Isso retoma a ideia de Clark; verifica-se que o samba (e todo universo a ele relacionado) foi o "material" do ator no seu trabalho, sua "opção". Ele poderia não ter escolhido corresponder ao perfil do público ou do circuito do entretenimento carioca, refutando a construção da imagem de homem brasileiro negro 
daquele momento. Não podemos omitir a ideia de que os personagens escritos para ele interpretar estavam de certa forma associados a um conjunto de fatores, tais como: a passagem do samba da "marginalidade" para o "centro", desdobrando outros ramos do ritmo; a nova forma de observar o homem negro na sociedade, relevando a sua contribuição na mestiçagem, um conceito que começava a ser mais fortalecido e positivado; e, por último, a convergência desses fatores que estavam coesos com as propostas político-ideólogicas do governo de Getúlio Vargas que queria aparentar uma imagem positiva do país, camuflando os problemas, inclusive, os raciais.

O samba e as marchinhas carnavalescas eram os principais ritmos brasileiros presentes nas revistas dos anos 1930. Composições de autores como Ary Barroso fizeram muito sucesso. O samba, cantado nas revistas, era o apologético nacionalista e o exaltação, os quais, segundo Cláudia Matos (1982), assim como outros derivados do samba, não estavam dissociados de suas apropriações pelas classes políticas e dominantes. As letras dessas músicas tinham como fio condutor a representação de um Brasil uno harmonioso e festivo, ideias coniventes com a propaganda ideológica da época. Segue o exemplo de um samba cantado no final da revista Maravilhosa, encenada em novembro de 1936 e com Otelo no elenco:

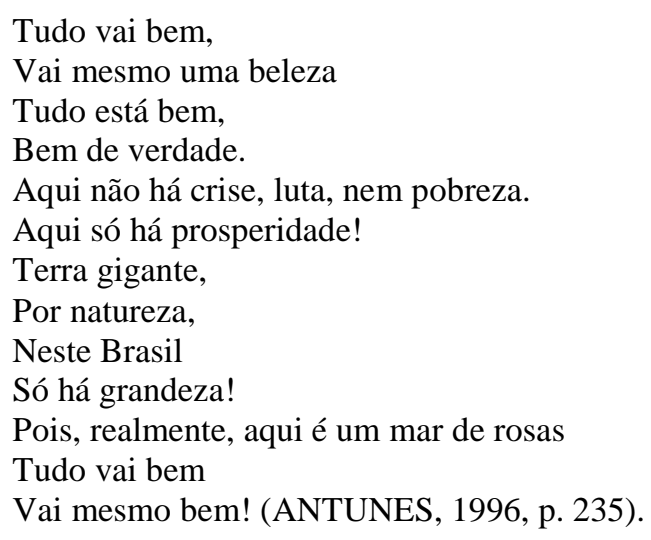

Porém, seria equívoco de nossa parte se desconsiderássemos a forma peculiar com que Otelo se relacionou com o samba, extraindo dele recursos corporais e vocais para usufruto nos diferentes momentos de sua trajetória. Isso nos pareceu esclarecido quando entramos em contato com a obra dele e percebemos suas passagens por uma heterogeneidade de linguagens, detectando uma mobilidade contínua por todas elas, seja na poesia, na música, no cinema novo, no cinema musical, no teatro dramático ou no teatro de revista. 
Se for traçada uma linha da vida artística de Otelo, será possível observar que sua proximidade mais visceral com o samba aconteceu no Rio de Janeiro, mais especificamente a partir de 1935.

Segundo o depoimento do próprio ator, ele conheceu o Rio quando passou a percorrer as ruelas da Lapa, subir os morros e frequentar as gafieiras e os ensaios das escolas de samba. Foi nesse momento que ele começou a sentir e viver o Rio de Janeiro. Assim, apesar de interpretar, em seus trabalhos, músicas que em sua maior parte faziam uma apologia a um Brasil harmônico e festivo, ele esteve em contato com realidades que possibilitaram dar dinamicidade para os tipos que interpretava ou iria interpretar. Estabelecendo contato, inclusive, com o samba malandro.

\section{Síncopa, malandragem e fronteira}

O ator para Grande Otelo era como um diamante bruto a ser lapidado ou como uma cachoeira violenta que se tem que dominar para gerar energia (STIGGER, 1979). Essa cachoeira violenta, o material de trabalho do ator, pode ser interpretada por inúmeras vias. Seja a que tem a referência técnica como sua base ou aquela que tem um conjunto de vivências acumuladas e originadas dos altos e baixos do ciclo vital. Pode ser a reunião das duas ideias, sendo a forma como se transita por elas o caráter dominador, colocado por Otelo, que proporcionará o resultado do trabalho na interpretação. Neste sentido, pode-se confirmar que realmente vida e arte se misturam num jogo de caminhos por ambas as áreas. Otelo parece ter transitado por aí cultivando sucessos e fracassos e a partir destes recomeçando sempre da estaca zero, reformulando ou transgredindo o estilo cômico de ser.

Cruzou pelas linguagens da arte movimentando "as águas da sua cachoeira". Conheceu a música operística e a música do morro, apreendeu a elocução de uma retórica formal e a língua das favelas. Dançou o fox-trot e o samba de gafieira. Ele viveu na fronteira e com a síncopa pulsando no seu corpo. E elas constituíam o seu estilo cômico interpretativo: "Síncopa, sabe-se, é a ausência no compasso da marcação de um tempo (fraco) que, no entanto repercute noutro mais forte" (SODRÉ, 1998, p. 11).

Esse elemento rítmico está presente nas músicas consideradas negras, como o samba, o jazz, o blues e a salsa. Além disso, seria o conector entre elas: 
De fato tanto no jazz quanto no samba, atua de modo especial a síncopa, incitando o ouvinte a preencher o tempo vazio com a marcação corporal - palmas, maneios, balanços, dança. É o corpo que também falta no apelo da síncopa. Sua força magnética, compulsiva mesmo, vem do impulso (provocado pelo vazio rítmico) de se completar a ausência do tempo com a dinâmica do movimento no espaço (Ibidem, p. 11).

No filme Carnaval Atlântida, dirigido por José Carlos Burle e produzido em 1953, Otelo faz o número No tabuleiro da baiana com a atriz Eliana Macedo. Essa mesma cena foi o divisor de águas na sua carreira quando a interpretou em 1937, com a atriz Déo Maia na Companhia do Jardel. Sua entrada na cena do filme é marcada por uma acrobacia. Ao longo do número, ele canta a música de Ary Barroso cortejando a baiana e executando movimentos rápidos do samba. A sua voz transita entre o registro de um cantor popular e o tom operístico consentido a partes específicas da letra: "Juro por Deus/ Pelo senhor do Bonfim/ Quero você/ Baianinha inteirinha pra mim e, em seguida, Tudo eu já fiz/ Já fui até no canjerê/ Pra ser feliz/ Meus trapinhos eu juntar com você". Com outras parceiras, por exemplo, quando realizou o dueto com a cantora Gal Costa, em 1981, ${ }^{2}$ o ator manteve o tom de ópera nessas mesmas partes, mas com um arremate debochado, inclusive modificando a letra da música com improviso e autonomia: "Quero você/ Gal gosta inteirinha pra mim”.

Neste trânsito, por alguns aspectos eruditos e populares, identificado em outras performances, podemos sugerir que sua interpretação tinha um jeito malandro de ser. Antes que nos equivoquemos em criar uma tendência de relação entre a malandragem e a rejeição ao trabalho e mesmo a burla em relação ao outro, traremos o conceito que Cláudia Matos, construiu quando discorreu sobre a filosofia malandra.

Para ela, a poética da malandragem é a poética da fronteira, da carnavalização e da ambiguidade. Deste modo um estilo ambivalente. O termo malandro é originário da palavra "maladros", cuja referência era feita aos sambistas de alguns morros do Rio de Janeiro:

Os sambistas do Estácio, que juntamente com a cidade nova, saúde, morro da favela, Gamboa, catumbi, morro de São Carlos, etc. formava o reduto de ex-escravos e seus descendentes, foram os primeiros a ostentar a designação de "maladros" e a orgulhar-se dela (MATOS, 1982, p. 41).

Para Matos, o samba malandro representa o universo negro-proletário dos morros em que existe um conjunto de códigos diferente daquele que rege a sociedade burguesa. É um samba com frestas, com espaços para crítica e contestação dessa 
sociedade. É um discurso dialógico. Contudo, essa crítica não pode ser considerada engajada ou até mesmo intencional. É satírica pelas suas referências. A figura mitológica do malandro está indissociada da figura do sambista.

A figura do homem malandro não se fixa em nenhum lugar, ele transita em todos os locais, morro ou asfalto, classe rica ou classe pobre: "Se o malandro transita na fronteira de classes é também para mostrar que ela está ali, ela existe” (Ibidem, p. 82).

A pesquisadora fez uma análise do discurso malandro no samba, atentando-se para as composições de Geraldo Pereira e Wilson Batista. Segundo ela, foram esses dois compositores que mais preservaram a veia malandra durante o Governo Vargas. Enquanto eram vigentes os sambas apologéticos e, posteriormente, os de cunho lírico amoroso, Pereira e Batista continuavam com suas letras permeadas de ideias ambivalentes acerca da sociedade pela combinação de um discurso formal com o informal sedimentado por gírias e colóquios.

[...] não parece que o autor ou os autores do samba visem expressamente a questionar a orientação moral e política dominante. Simplesmente o sambista fala aí uma linguagem da "fresta": ainda que seu discurso pareça assumir uma postura ideologicamente "recomendável", ele se revela simultaneamente cheio de rachaduras pelas quais emerge um outro discurso, que problematiza ou até neutraliza o primeiro (Ibidem, p. 91).

O discurso e a atitude cômicos também seriam uma linguagem de "fresta", pois é uma linguagem de sátira mesmo que não a tenha como primeiro objetivo, pois afinal de contas a meta maior é sempre fazer a plateia rir e o riso tem um efeito corretivo, segundo Bergson. Grande Otelo, como ator cômico que também era, assumia essa identidade.

Sua presença frequente na Lapa, na Praça Onze, nos morros e na Gafieira Elite ${ }^{3}$ proporcionou sua imersão no universo do samba. Sua vida boemia assumida cultivou de certa forma uma parte essencial do seu material de trabalho.

Consolidado como o homem show no Cassino da Urca, na década de 1940, usou e abusou de todas as suas armas cômicas, imitando personalidades e parodianddo cenas: "Vestia-se, por exemplo, de palhaço e fazia uma paródia engraçadíssima da ópera Palhaços, de Ruggero Leoncarvalho" (CABRAL, 2007, p. 83). Cantava sambas exibindo com propriedade o aprendizado nos circuitos populares que frequentava, mas cantava também em espanhol, francês e inglês. Não é difícil de imaginar que mesmo passeando por outras línguas, seu deboche irrompia. 
O manuseio malandro e sincopado de suas ferramentas lhe dava autonomia para realizar efeitos surpresas no palco, como no caso da aposta entre ele e os jornalistas da Revista Diretrizes, em 1941 que o questionou durante uma entrevista, em meio ao seu show na Urca, se ele era capaz de fazer a platéia chorar. Otelo aceitou a aposta. Esperando por mais um número cômico, o público assistiu satisfatoriamente a um número dramático. Dentro de um espaço concebido para divertir, o ator "manipulou" cenicamente a plateia suscitando um efeito contrário ao riso. Essa "manipulação" (Otelo) articulada a "distração" (plateia) já implica em um efeito cômico subjacente. A experiência só foi bem-sucedida porque o ator dominou a sua "cachoeira violenta" e "gerou a energia" cênica para o drama. Mostrando que também era um ator na fronteira do fazer rir e do fazer chorar (Cf. DOURADO, 2005).

A figura malandra é caracterizada pela ginga, maleabilidade, dinâmica e habilidade no jogo corporal. Uma figura móvel, transitando por vários sentidos. Tomamos as imagens dos filmes musicais brasileiros em que Otelo participou como suporte de análise, visto que muitas cenas, de acordo com alguns estudiosos, tinham concepções semelhantes com as cenas revisteiras.

Segundo a autora Rosângela de Oliveira Dias (1993), as chanchadas tinham inspiração no teatro ligeiro, circo, rádio, carnaval e teatro musicado. Ela faz muitas observações sobre as atuações de seus intérpretes, identificando questões semelhantes nos estudos sobre o teatro popular, em especial, o de revista, são elas: postura cênica nada naturalista ou convencional; gestuais influenciados pelo circo; conjunto diverso de expressões e caretas; malabarismos; e o famoso "pulo do gato", que consistia numa técnica de atuação caracterizada pela irreverência, caricatura, malícia e a interpretação popular - jocosa. Os atores e as atrizes do cinema musical, assim como no gênero revisteiro, interpretavam "tipos" assimiláveis pelo público. Eles eram semelhantes em diversos filmes.

Nos filmes musicais Também somos irmãos (1949), Aviso aos navegantes (1951), Barnabé tu és meu (1952), Amei um bicheiro (1953), A dupla do barulho (1953), Carnaval Atlântida (1953) e Matar ou correr (1954), Otelo apresenta uma forma de movimentação muito próxima da encontrada no circuito do samba carioca. Volteios, parecidos com os da figura do Mestre Sala. Galanteios, semelhantes aos do malandro. Passos rápidos ramificados de um típico passista. Sobe e desce do corpo com uma flexibilidade típica de um bailarino. E, ao mesmo tempo em que o ritmo do seu 
corpo era cadenciado, tinha uma característica vocal, considerada por muitos críticos como "esganiçada", usada em muitos dos tipos por ele interpretados.

Além disso, percebemos que, com exceção dos filmes $A$ dupla do barulho e Matar ou correr, todos os seus personagens, assim como os estudados nas revistas da Companhia de Jardel Jércolis, têm relações com o mundo do samba. Se essa ligação não é explicitada de forma direta ela fica implícita na sua técnica de atuação, por meio de pequenos gestos e movimentos como a malemolência da fala, o pisado macio e ginga da capoeiragem. Mas isso não impede de outras imbricações aparecerem como a retórica formal e os movimentos circenses tipo cambalhotas e pequenas insinuações de um palhaço subentendido.

A referência "sambística" do ator coincide com a visão de Sodré que diz que o samba não pode ser apenas interpretado como tática de resistência da cultura afrobrasileira, pois cairíamos no perigo de deduzi-lo ou sugerir sua existência a partir da cultura dominante. Esse ritmo é um espaço de troca, além de ser um universo de sentidos alternativos que se inserem mutuamente.

O corpo de ator de Grande Otelo, influenciado pela síncopa dessa prática afrobrasileira, era fronteiriço porque nela se assentou. Isso era uma espécie de recurso, de um material ideológico e de trabalho que o ator escolheu.

\section{Referências}

\section{Livros}

ANTUNES, Delson dos Santos. O homem do tró-ló-ló: Jardel Jércolis e o Teatro de Revista Brasileiro (1925-1944). Dissertação (Mestrado em Teatro) - Centro de Letras e Artes, Universidade Federal do Estado do Rio de Janeiro, Rio de Janeiro, 1996.

BERGSON, Henri. O riso - Ensaio sobre a significação da comicidade. 2. ed. Trad. Ivone Castilho Benedetti. São Paulo: Martins Fontes, 2007.

CABRAL, Sérgio. Grande Otelo, Uma biografia. São Paulo: Ed. 34, 2007.

CLARK, Timothy J. As condições da criação artística. In: SALZSTEIN, Sônia (Org.). Modernismos: ensaio sobre política, história e teoria da arte: T. J. Clark. São Paulo: Cosac Naify, 2007, p. 331-339.

DIAS, Rosângela de Oliveira. O mundo como chanchada: cinema e imaginário das classes populares na década de 50. Rio de Janeiro: Relume-Dumará, 1993. 
DOURADO, Ana Karicia Machado. Fazer rir, fazer chorar, a arte de Grande Otelo. Dissertação (Mestrado em História Social) - Faculdade de Filosofia, Letras e Ciências Humanas, Universidade de São Paulo, São Paulo, 2005.

MATOS, Cláudia. Acertei no milhar: samba e malandragem no tempo de Getúlio. Rio de Janeiro: Paz e Terra, 1982.

MENCARELLI, Fernando. Cena aberta. A absolvição de um bilontra e o teatro de revista de Arthur Azevedo. Campinas: Unicamp, 1999.

RUIZ, Roberto; Brandão, Tânia. O teatro de revista no Brasil: das origens à Primeira Guerra Mundial. Rio de Janeiro: Inacen, 1988.

SODRÉ, Muniz. Samba, o dono do corpo. 2. ed. Rio de Janeiro: Mauad, 1998.

VENEZYANO, Neide. O teatro de revista no Brasil: dramaturgia e convenções. Campinas: Unicamp, 1991. 1996. Não adianta chorar: teatro de revista brasileiro... Oba! Campinas: Unicamp,

\section{Vídeos}

A DUPLA do barulho. Direção: Carlos Manga. Produção: Atlântida Cinematográfica. Intérpretes: Grande Otelo, Oscarito e outros. Roteiro: Víctor Lima, Guido Martineli e Carlos Manga. 1953. 1 DVD, full screen (90min), P e B.

AMEI um bicheiro. Direção: Jorge Ileli e Paulo Wanderley. Produção: Atlântida Cinematográfica. Intérpretes: Grande Otelo, Oscarito, Eliana Macedo e outros. Roteiro: Marcelo Dória e Jorge Ileli. 1952. 1 DVD full screen (88 min), P e B.

AVISO aos navegantes. Direção: Watson Macedo. Produção: União Cinematográfica Brasileira S.A e Atlântida Empresa Cinematográfica do Brasil S.A. Intérpretes: Oscarito, Grande Otelo, Anselmo Duarte, José Lewgoy, Adelaide Chiozzo e outros. Roteiro: Alinor Azevedo e Paulo Machado. 1950. 1 DVD full screen (1:1'37), P e B.

BARNABÉ tu és meu. Direção: José Carlos Burle. Produção: Décio Alves Tinoco. Intérpretes: Grande Otelo, Oscarito e outros. Roteiro: José Carlos Burle. 1952. 1 DVD full screen (90min), P e B.

CARNAVAL, Atlântida. Direção: José Carlos Burle. Produção: Atlântida Cinematográfica. Intérpretes: Grande Otelo, Colé, Eliana Macedo, Oscarito e outros. Roteiro: Carlos Burle, Victor Lima e Berliet Júnior. 1953. 1 DVD, full screen (95min), $\mathrm{P}$ e B.

MATAR ou correr. Direção: Carlos Manga. Produção: Atlântida Cinematográfica. Intérpretes: Grande Otelo, Eliana Macedo, Oscarito, John Hebert e outros. Roteiro: Amleto Daissé e Victor Lima. 1954. 1 DVD full screen (87 min), P e B. 
TAMBÉM somos irmãos. Direção: José Carlos Burle. Produção: Atlântida Empresa Cinematográfica do Brasil S.A. Intérpretes: Grande Otelo, Aguinaldo Camargo, Vera Nunes, Jorge Dória, Agnaldo Rayol, Ruth de Souza e outros. Roteiro: Alinor Azevedo. 1949. 1 DVD full screen (85min), P e B.

\section{Periódico}

STIGGER, Ivo Egon. Grande Otelo: minha força de ator é herança ancestral ligada à formação da raça brasileira. Correio do Povo, Porto Alegre, 11 jan. 1979.

\section{Fonte on-line}

http://www.youtube.com/watch?v=K9G3daDFszE\&feature=related. Acessado em: 5 out. 2010 .

\footnotetext{
${ }^{1}$ Este termo é vigente desde a segunda metade do século XIX para designar textos teatrais e espetáculos que correspondem ao drama, à tragédia e à alta comédia, em contraponto aos estilos populares, como as revistas e os gêneros ligeiros (Cf. MENCARELLI, 1999).

2 Trecho do especial "Grandes Nomes" com a cantora Gal Costa e Grande Otelo cantando No tabuleiro da baiana, exibido em 1981 pela TV Globo. Disponível em: http://www.youtube.com/watch?v=K9G3daDFszE\&feature=related. Acesso em: 5 out. 2010.

${ }^{3}$ Clube de Gafieira fundado em 1930 pelo comerciante Júlio Simões, a quem Grande Otelo sempre se referiu com muita estima. Verificar sobre o assunto nas suas biografias, escritas por Roberto Moura e Sérgio Cabral (2007).
} 